\title{
Follow-Up Results of a Phase II Study of Ibritumomab Tiuxetan Radioimmunotherapy in Patients with Relapsed or Refractory Low-Grade, Follicular, or Transformed B-Cell Non-Hodgkin's Lymphoma and Mild Thrombocytopenia
}

\author{
Russell Schilder, ${ }^{1}$ Arturo Molina, ${ }^{2}$ Nancy Bartlett, ${ }^{3}$ Thomas Witzig, ${ }^{4}$ Leo Gordon, ${ }^{5}$ \\ James Murray, ${ }^{6}$ Stewart Spies, ${ }^{5}$ Hua Wang, ${ }^{2}$ Gregory Wiseman, ${ }^{4}$ and Christine White ${ }^{2}$ \\ ${ }^{1}$ Fox Chase Comprehensive Cancer Center, Philadelphia, PA \\ ${ }^{2}$ Biogen Idec, San Diego, CA \\ ${ }^{3}$ Washington University, St. Louis, MO \\ ${ }^{4}$ Mayo Clinic, Rochester, MI \\ ${ }^{5}$ Northwestern University, Chicago, IL \\ ${ }^{6}$ M.D. Anderson Cancer Center, Houston, TX
}

\begin{abstract}
This report presents updated time-to-event variables from a multicenter phase II trial of reduced-dose ${ }^{90} Y$ ibritumomab tiuxetan in patients with relapsed or refractory low-grade, follicular, or transformed B-cell non-Hodgkin's lymphoma (NHL) and mild thrombocytopenia (platelet counts of 100 to $149 \times 10^{9}$ platelets/L). Patients received a single course of ibritumomab tiuxetan radioimmunotherapy, with ${ }^{90} Y \mathrm{ib}$ ritumomab tiuxetan administered at $0.3 \mathrm{mCi} / \mathrm{kg}$ (compared to a standard dose of $0.4 \mathrm{mCi} / \mathrm{kg}$ ). In $30 \mathrm{pa}$ tients, the overall response rate was 83\%, with complete responses (confirmed [CR] and unconfirmed [CRu]) of 47\%. Median follow-up time is currently 36.5 months (range: 7.5-54.9 months). Median duration of response was 11.5 months (range: 1.0-53.9 months), median time to progression was 9.4 months (range: 1.7-54.8+ months), and median time to next lymphoma therapy was 14.6 months (range: 2.3-54.9+ months). Median overall survival time has not yet been reached. Long-term responses, defined as time to progression of 12 months or greater, have been seen in 14 of 30 patients (47\%) overall, and 12 of 14 CR/CRu patients (86\%). Toxicities were primarily hematologic and reversible. No additional long-term adverse events have been observed in the follow-up period, and treatment did not preclude subsequent lymphoma therapies.
\end{abstract}

Key words: ibritumomab tiuxetan, radioimmunotherapy, non-Hodgkin's lymphoma, therapy, thrombocytopenia

Address reprint requests to: Russell Schilder; Department of Medical Oncology, Fox Chase Comprehensive Cancer Center, 333 Cottman Avenue, Philadelphia, PA 19112412; Tel.: (215) 728-3545; Fax: (215) 728-3639

E-mail: RJ_Schilder@fccc.edu

\section{INTRODUCTION}

The clinical course of low-grade or follicular Bcell non-Hodgkin's lymphomas (NHL) is characterized by initial responsiveness to therapy and 
a continuous pattern of multiple remissions and relapses. Patients usually receive several different lymphoma therapies over the course of their disease. Persistent mild thrombocytopenia is seen in a number of patients with relapsed or refractory NHL, and may be indicative of compromised bone marrow reserve from prior therapy, lymphomatous bone marrow involvement, or both. Patients with baseline thrombocytopenia are at increased risk for chemotherapy-induced myelosuppression and its associated complications. ${ }^{1}$ As such, the treatment of patients with low-grade or follicular B-cell NHL and persistent mild thrombocytopenia presents a clinical challenge.

Radioimmunotherapy with ibritumomab tiuxetan is an effective treatment option for patients with relapsed or refractory low-grade, follicular, or transformed B-cell NHL. ${ }^{2-4}$ It was recognized early in the clinical development of ibritumomab tiuxetan that baseline platelet count, an indicator of bone-marrow reserve, correlated with the risk of hematologic toxicity. Early in the phase I/II study, investigators noted that patients with baseline mild thrombocytopenia treated with ${ }^{90} \mathrm{Y}$ ibritumomab tiuxetan at a dose of $0.4 \mathrm{mCi} / \mathrm{kg}$ were at an increased risk of grade 4 hematologic toxicity, compared to patients with normal baseline platelet counts. $^{2}$ Thereafter, patients with mild thrombocytopenia, defined as a baseline platelet count of 100 to $149 \times 10^{9}$ platelets $/ \mathrm{L}$, received a reduced dose of ${ }^{90} \mathrm{Y}$-ibritumomab tiuxetan of $0.3 \mathrm{mCi} / \mathrm{kg}$.

Subsequently, a phase II trial was conducted to evaluate the safety and efficacy of reduced-dose ${ }^{90} \mathrm{Y}$ ibritumomab tiuxetan radioimmunotherapy in 30 patients with relapsed or refractory lowgrade, follicular, or transformed B-cell NHL and mild thrombocytopenia (platelet counts of 100 to $149 \times 10^{9}$ platelets/L). Results from this study were first reported in $2002 .{ }^{5}$ Patients received a single course of treatment, in which ${ }^{90} \mathrm{Y}$ ibritumomab tiuxetan was administered at a dose of $0.3 \mathrm{mCi} / \mathrm{kg}$. The overall response rate was $83 \%$ using International Workshop response criteria. ${ }^{6}$ Toxicities were primarily hematologic, and were transient and reversible. This report provides updated data on response and survival outcomes from an additional 2 years of follow-up time.

\section{METHODS}

A detailed description of the design and methods of this single-arm, multicenter phase II study has been previously reported. ${ }^{5}$ Briefly, patients age
18 or above with histologically confirmed relapsed or refractory low-grade, follicular, or transformed CD20+ NHL and mild thrombocytopenia, defined as a baseline platelet count 100 to $149 \times 10^{9}$ platelets/L were eligible for enrollment. Patients had to have bidimensionally measurable disease, with at least 1 lesion measuring $2.0 \mathrm{~cm}$ or greater in a single dimension. Additional eligibility criteria included less than $25 \%$ bone marrow involvement; baseline World Health Organization (WHO) performance status of 0,1 , or 2 ; no prior myeloablative therapy; and no prior radioimmunotherapy or anti-CD20 therapy. Patients had to have otherwise adequate hematologic and hepatic function and provide written, informed consent.

On day 1 of therapy, patients received an i.v. infusion of rituximab $250 \mathrm{mg} / \mathrm{m}^{2}$ followed by an imaging dose of ${ }^{111}$ In ibritumomab tiuxetan 5 $\mathrm{mCi}(185 \mathrm{MBq})$. Provided biodistribution was adequate on gamma-camera images, approximately 1 week later patients received a second infusion of rituximab $250 \mathrm{mg} / \mathrm{m}^{2}$, followed by ${ }^{90} \mathrm{Y}$ ibritumomab tiuxetan $0.3 \mathrm{mCi} / \mathrm{kg}(11 \mathrm{MBq} / \mathrm{kg})$, up to a maximum dose of $32 \mathrm{mCi}(1.2 \mathrm{GBq})$.

\section{Statistical Design}

The primary study endpoint was overall response rate $(\mathrm{ORR})$, with complete response $(\mathrm{CR} / \mathrm{CRu})$ rate, partial response (PR) rate, time to progression (TTP), duration of response (DR), and time to next NHL therapy (TTNT) evaluated as secondary endpoints. Response rates were determined using International Workshop NHL response criteria. ${ }^{6}$

Definitions for time-to-event variables were as follows: TTP was the time interval between the date of the first treatment infusion to the date of progression or date of last known contact for censored patients; DR was the time interval between the date of the first IWRC response and the date of disease progression; TTNT was the time interval between the date of the first treatment infusion to the date of the first subsequent NHL therapy; overall survival (OS) was the time interval between the date of the first treatment infusion to date of death or last cutoff date for censored patients. Median TTP, DR, TTNT, and OS were estimated using the Kaplan-Meier method. ${ }^{7}$

\section{RESULTS}

The study enrolled a total of 30 patients between May 1998 and August 1999, with a current fol- 
low-up through August 2003, for a median follow-up time of 36.5 months (range: $7.5-54.8+$ months). All 30 patients enrolled were evaluable for response and toxicity. Baseline patient characteristics are listed in Table 1. Patients had received a median of 2 prior therapies for NHL (range: 1-9). Nineteen (19) patients (63\%) were resistant to at least 1 prior chemotherapy, and 14 patients $(47 \%)$ were resistant to their last chemotherapy. Resistance was defined as a failure to achieve a complete or partial response, or disease progression, within 6 months.

Overall, 25 of 30 patients $(83 \%)$ responded to therapy, with $11 \mathrm{CR}(37 \%), 3 \mathrm{CRu}(10 \%)$ and 11 PR (37\%) by International Workshop response criteria. ${ }^{6}$ The median duration of response was 11.5 months (range: 1.0-53.9 months). The median time to progression for all patients was 9.4 months (range: 1.7-54.8+ months) (Fig. 1). Overall, responses have been durable. Long-term responses, defined as time to progression of 12 months or greater, has been seen in 14 of 30 patients $(47 \%)$ overall, including 12 of 14 patients (86\%) who achieved a CR or CRu (the 2 patients

\begin{tabular}{|c|c|c|}
\hline Characteristic & No. & $\%$ \\
\hline \multicolumn{3}{|l|}{ Sex } \\
\hline Male & 18 & 60 \\
\hline Female & 12 & 40 \\
\hline Median age (yrs.), range & $61(29-85)$ & \\
\hline \multicolumn{3}{|l|}{ Histology } \\
\hline Small lymphocytic lymphoma & 2 & 7 \\
\hline Follicular & 25 & 83 \\
\hline Transformed & 3 & 10 \\
\hline \multicolumn{3}{|l|}{ Disease stage } \\
\hline $\mathrm{I} / \mathrm{II}$ & 3 & 10 \\
\hline III/IV & 27 & 90 \\
\hline \multicolumn{3}{|l|}{ Degree of bone marrow involvement } \\
\hline 0 to $<5 \%$ & 10 & 33 \\
\hline $5 \%$ to $20 \%$ & 12 & 40 \\
\hline $20 \%$ to $<25 \%$ & 8 & 27 \\
\hline \multicolumn{3}{|l|}{ No. of extranodal disease sites } \\
\hline 0 or 1 & 24 & 80 \\
\hline 2 or more & 6 & 20 \\
\hline \multicolumn{3}{|l|}{ Tumor size } \\
\hline$<5 \mathrm{~cm}$ & 16 & 53 \\
\hline 5 to $<7 \mathrm{~cm}$ & 9 & 30 \\
\hline 7 to $<10 \mathrm{~cm}$ & 3 & 10 \\
\hline $10 \mathrm{~cm}$ or more & 2 & 7 \\
\hline Splenomegaly & 7 & 23 \\
\hline $\begin{array}{l}\text { Median no. of prior chemotherapy } \\
\text { (range) }\end{array}$ & $2(1-9)$ & \\
\hline
\end{tabular}

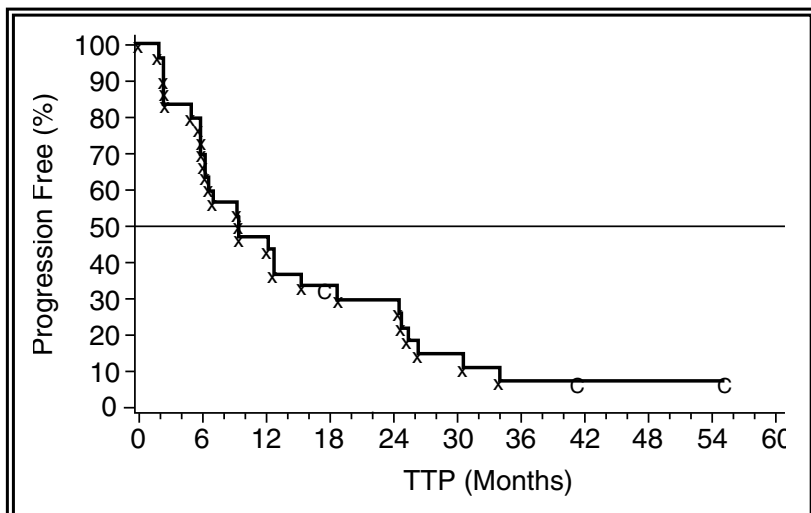

Figure 1. Time to progression $(\mathrm{n}=30)$; median time to progression $=9.4$ months.

who relapsed within 12 months were true CRs, not CRus). Median TTP in the 14 patients achieving long-term responses of 12 months or greater was 24.6 months (range: 12.1-54.8+ months), and median TTP in all CR/CRu patients (independent of $\mathrm{CR} / \mathrm{Cru}$ duration) was 24.5 months (range: 4.9-54.8 months). Two (2) patients had long-term partial responses of 12.6 and 17.3 months, respectively. These 2 patients had a residual mass on computed tomography (CT) scan that did not meet CRu criteria but was more likely fibrosis/scar than viable tumor, accounting for the long duration of response. Functional imaging with positron emission tomography (PET) was not done, but may have better defined these residual masses. Two (2) of the patients have remained in continuous, complete remission for 41 and 54.8+ months, respectively, following ibritumomab tiuxetan radioimmunotherapy.

Median overall survival time has not yet been reached (data not shown). Overall median TTNT was 14.6 months (range: $2.3-54.8+$ months). A total of 24 patients received treatment subsequent to ibritumomab tiuxetan radioimmunotherapy, including rituximab, chemotherapy, and other therapies. In the 13 patients who received rituximab as their first NHL treatment following ibritumomab tiuxetan radioimmunotherapy, clinical responses were observed in 6 patients, 3 patients did not respond to therapy, and clinical outcome was unknown in the remaining 4 patients.

At this time, 7 of 30 patients enrolled in this study have died; 6 deaths were the result of disease progression, and 1 death was the result of other causes. In the original report, 1 patient with a history of chronic alkylator exposure developed acute myelogenous leukemia 20 months after 
study entry. With longer follow-up, there have been no additional cases of secondary malignancies or other long-term toxicities in this patient cohort.

\section{DISCUSSION}

In this phase II trial, 30 patients with relapsed or refractory low-grade, follicular, or transformed B-cell NHL and mild thrombocytopenia received a single course of radioimmunotherapy, with ${ }^{90} \mathrm{Y}$ ibritumomab tiuxetan administered at a reduced dose of $0.3 \mathrm{mCi} / \mathrm{kg}$. Overall, $83 \%$ of patients responded to therapy, with 14 patients (47\%) achieving a $\mathrm{CR}$ or $\mathrm{CRu}$. Responses have been durable, with 14 of 30 patients overall, and 12 of $14 \mathrm{CR} / \mathrm{CRu}$ patients, having a time to disease progression in excess of 12 months. Median TTP for all patients was 9.4 months, with a median TTNT of 14.6 months. In the 14 patients with long-term responses, median TTP was 24.6 months. At this time, median overall survival time has not yet been reached.

With respect to safety, toxicities were primarily hematologic, but were transient and reversible. ${ }^{5}$ With extended follow-up, no long-term adverse effects were noted, consistent with data previously indicating that treatment with ibritumomab tiuxetan radioimmunotherapy is not associated with an increased risk of secondary malignancies. ${ }^{8}$ Recent reports have indicated that subsequent NHL therapies, such as chemotherapy, immunotherapy, and even high-dose therapy with stem-cell or bone-marrow transplant, can be safely administered to patients who have previously received ${ }^{90} \mathrm{Y}$ ibritumomab tiuxetan radioimmunotherapy. ${ }^{9,10}$ In this study, 24 of 30 patients received one or more subsequent NHL therapies.

\section{CONCLUSION}

Persistent mild thrombocytopenia in patients with relapsed or refractory NHL is indicative of impaired bone-marrow reserves, either from prior chemotherapy, lymphomatous bone marrow involvement, or both. For these patients, treatment with reduced-dose ${ }^{90} \mathrm{Y}$ ibritumomab tiuxetan is an effective option, producing a high rate of re- sponse and durable remissions. Therapy is generally well tolerated, and does not preclude the use of other subsequent lymphoma therapies.

\section{ACKNOWLEDGMENTS}

The authors wish to thank Christine Gutheil for her editorial assistance and Jessica Olson for her technical assistance.

\section{REFERENCES}

1. Blay JY, Le Cesne A, Mermet C, et al. A risk model for thrombocytopenia requiring platelet transfusion after cytotoxic chemotherapy. Blood 1998;92:405.

2. Witzig TE, White CA, Wiseman GA, et al. Phase I/II trial of IDEC-Y2B8 radioimmunotherapy for treatment of relapsed or refractory CD20+ B-cell non-Hodgkin's lymphoma. J Clin Oncol 1999;17:3793.

3. Witzig TE, Gordon LI, Cabanillas F, et al. Randomized controlled trial of yttrium-90-labeled ibritumomab tiuxetan radioimmunotherapy versus rituximab immunotherapy for patients with relapsed or refractory low-grade, follicular, or transformed B-cell non-Hodgkin's lymphoma. J Clin Oncol 2002;20:2453.

4. Witzig TE, Flinn IW, Gordon LI, et al. Treatment with ibritumomab tiuxetan radioimmunotherapy in patients with rituximab-refractory follicular non-Hodgkin's lymphoma. J Clin Oncol 2002;20:3262.

5. Wiseman GA, Gordon LI, Multani PS, et al. Ibritumomab tiuxetan radioimmunotherapy for patients with relapsed or refractory non-Hodgkin's lymphoma and mild thrombocytopenia: A phase II multicenter trial. Blood 2002;99:4336.

6. Cheson, B, Horning S, Coiffier B, et al. Report of an international workshop to standardize response criteria for non-Hodgkin's lymphoma. J Clin Oncol 1999;17:1244.

7. Kaplan E, Meier P. Nonparametric estimation for incomplete observations. J Am Stat Assoc 1958;53:457.

8. Cruzman M, Witzig TE, Gaston J, et al. Zevalin radioimmunotherapy is not associated with an increased incidence of secondary myelodysplastic syndrome (MDS) or acute myelogenous leukemia (AML). Blood 2002;100:357a:abstr.1386.

9. Ansell SM, Ristow KM, Haberman TM, et al. Subsequent chemotherapy regimens are well tolerated after radioimmunotherapy with yttrium-90 ibritumomab tiuxetan for non-Hodgkin's lymphoma. J Clin Oncol 2002; 20:3885.

10. Schilder RJ, Witzig T, Gordon L, et al. ${ }^{90} \mathrm{Y}$ ibritumomab tiuxetan (Zevalin) radioimmunotherapy does not preclude effective delivery of subsequent therapy for lymphoma. [abstr. 1064] Proc Am Soc Clin Oncol 2002;21:267A. 